\title{
STUDY OF ANTHROPOMETRIC PARAMETERS AND PULMONARY FUNCTION TESTS OF SWIMMERS OF INDORE CITY
}

\author{
Amarjeet Singh Chhabra, Ameet Julka, Manjula Mehta
}

1. Assistant Professor, Department of Physiology, M.G. M Medical College, Indore, Madhya Pradesh.

2. Assistant Professor, Department of Anatomy, M.G.M Medical College, Indore, Madhya Pradesh.

3. Demonstrator, Department of Physiology, M.G.M Medical College, Indore, Madhya Pradesh.

\section{CORRESPONDING AUTHOR:}

Dr. Amarjeet Singh Chhabra,

155-b, Amitesh Nagar scheme no. 59,

Indore, Madhya Pradesh- 452014.

E-mail: amarjeet_singh_c@rediffmail.com

ABSTRACT: BACKGROUND: It is well known that exercise has a significant effect on respiratory functions. Swimming is considered to be a very good exercise for maintaining proper health and also has a profound effect on the lung functions of an individual; the present study was carried out in 60 young male adults of Eighteen to Thirty years of age group to assess their Anthropometric parameters and Pulmonary Functions METHODS: Thirty male swimmers who used to swim for at least two years regularly were compared with age and sex matched thirty controls who were not involved in any routine exercise. Lung volumes were recorded by Pulmonary Function test machine and analyzed statistically. RESULTS AND CONCLUSION: It was found that Lung volumes were higher in swimmers. Swimming exercise affects lung volume measurements as respiratory muscles including the diaphragm of swimmers are required to develop greater pressure as a consequence of immersion in water during respiratory cycle. This may lead to functional improvement in these muscles and also alterations in elasticity of lung and chest wall or of ventilatory muscles, leading to an improvement in forced vital capacity and other lung functions of swimmers.

KEY WORDS: Swimmers, Pulmonary Functions

INTRODUCTION: Regular exercise produces many changes in the body that result with the lungs being able to function more positively. Swimming strengthens the body, helps relax the mind, regulates breathing, stimulates circulation and helps improve lung capacity. Unlike specific weight training exercises or running, swimming benefits the upper body, torso and legs together and it will improve general strength, lung capacity, stamina and cardiovascular fitness. It is well known that swimming has a significant effect on respiratory functions [1, 23]. It is an aerobic exercise that helps the lungs to use oxygen efficiently. Aerobic exercise helps large muscle groups and elevates heart rate, which makes your lungs work efficiently. The purpose of choosing swimmers instead of any other sportspersons was that previous studies in this field have shown that swimmers have higher values of lung volumes as compared to any other sports $[4,5]$.

AIMS AND OBJECTIVES: The aim of the present study was to investigate and report anthropometric parameter and pulmonary functions of swimmers of Indore city and compare these values with the pulmonary functions of young healthy adults of same age group not routinely engaged in any specific exercise. 
MATERIALS AND METHODS: The present study was conducted on 30 male swimmers and 30 male controls in the age groups of 18-30 years. The swimmers were selected from various swimming pools from Indore city period. The controls were healthy male medical students, not routinely engaged in any specific exercise $(n=30)$. All the subjects were clinically examined to rule out any respiratory disorder.

The study was approved by the ethical committee of the institution and a written informed consent was taken from all the individuals of study and control group in accordance with the protocol.

The pulmonary function tests were recorded with the help of modern computerized pulmonary function test machine manufactured by Ganshorn Medizin Electronic (Gmbh) Germany.

Lung function parameters (Forced Vital capacity, FVC; Tidal volume, TV; Inspiratory vital capacity, IVC; Inspiratory reserve volume, IRV; Expiratory reserve volume, ERV; forced expiratory volume in first second, $\mathrm{FEV}_{1}$; Peak Expiratory flow rate, PEFR; Maximum Expiratory Flow rate, MEFR) were recorded on Spirometer. Measuring scale stand was used for measuring height in centimeters. Electronic weighing machine was standardized and used for measuring weight in kilograms.

An interview schedule was used for all subjects in the study to obtain information related to age, socioeconomic status with relevant personal and family history. Kuppuswamy's Socioeconomic Status Scale including criteria like education, occupation, and family income was used and accordingly individuals belonging to middle class family on the basis of this scale were included. Personal history included diet, addiction if any to smoking, alcoholism or others. Height and weight were measured while the subject was standing erect on a plain platform without shoes. Every subject was wearing routine outfit while recording the weight.

STATISTICAL ANALYSIS: Done using SPSS software version 21. Statistical calculation was done by independent sample ' $t$ ' test. A p value of $<0.05$ was considered significant

RESULTS: The measured anthropometric factors (height $176.59 \pm 5.69 \mathrm{cms}$, weight $65.63 \pm$ $8.62 \mathrm{~kg}$, and body surface area $1.80 \pm 0.12 \mathrm{~m}^{2}$ ) were higher and statistically significant in the swimmer than the control groups $\left(169.9 \pm 6.09 \mathrm{cms}, 59.73 \pm 8.73 \mathrm{~kg}, 1.68 \pm 0.13 \mathrm{~m}^{2}\right)$ respectively $(\mathrm{p}<0.05$, Table 1$)$.

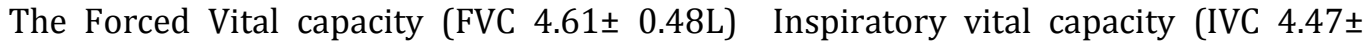

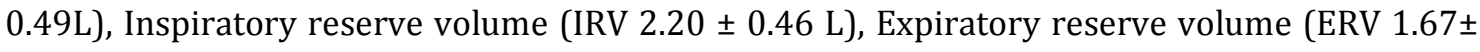
$0.31 \mathrm{~L})$, Forced expiratory volume in first second ( $\left.\mathrm{FEV}_{1} 4.16 \pm 0.41 \mathrm{~L} / \mathrm{second}\right)$, Maximum Expiratory Flow rate at $25 \%$ of vital capacity (MEF $25 \% 2.97 \pm 0.76 \mathrm{~L} /$ second) ,Maximum Expiratory Flow rate at $50 \%$ of vital capacity and (MEF $50 \%, 5.85 \pm 0.97 \mathrm{~L} /$ second ) were higher and statistically significant in the swimmer than the control groups( FVC $3.61 \pm 0.27 \mathrm{~L}$, IVC $3.46 \pm$ 0.27L,IRV $1.6 \pm 0.33 \mathrm{~L}$, ERV $1.32 \pm 0.35 \mathrm{~L}, \mathrm{FEV}_{1} 3.31 \pm 0.26 \mathrm{~L} /$ second, (MEF $25 \%, 2.46 \pm 0.60$ $\mathrm{L} /$ second and MEF $50 \% 5.26 \pm 1.13 \mathrm{~L} /$ second) respectively. $(\mathrm{p}<0.05$, Table 2$)$

Tidal volume (TV 0.77 $\pm 0.27 \mathrm{~L}$ ), Maximum Expiratory Flow rate between $25-75 \%$ of vital capacity (MEF 25-75 \%, 5.14 \pm 0.86 L/second), Maximum Expiratory Flow rate between 75-85 $\%$ of vital capacity(MEF 75-85 \%,7.67 $\pm 1.42 \mathrm{~L} /$ second) and Peak Expiratory flow rate (PEFR $8.27 \pm 1.23 \mathrm{~L} /$ second) were higher but statistically not significant in swimmer as compared to in control group (TV 0.69 \pm 0.16 L, MEF 25-75 \% 4.54 \pm 0.87 L/second, MEF 75-85 \%, 7.10 \pm 1.84 $\mathrm{L} /$ second and PEFR 7.10 $\pm 1.59 \mathrm{~L} /$ second) respectively. 
The values of FEV1 as percentage of FVC were significantly higher in control group $(91.2 \pm 5.53$ $\%)$ as compared to swimmer $(83.81 \pm 7.02 \%)(\mathrm{p}<0.05$, Table 2$)$.

DISCUSSION: The results discussed above clearly indicate that swimmers had higher values of lung functions compared to the controls, thereby confirming that regular swimming has a facilitating effect on the lungs. Similar results have been obtained by other workers in this field $[6,7,8,9]$. The large metabolic demand of strenuous exercise requires an efficient oxygen transport system from the atmosphere to the active tissues. The results of the present study support the idea that physical training has a facilitative effect on ventilatory function and physically active persons have greater lung function values in comparison to sedentary persons $[10,11,12,13,14]$.

During swimming respiratory muscles including diaphragm of swimmers are required to develop greater pressures as a consequence of immersion during the respiratory cycle and this may lead to a functional improvement in these muscles. Also possibilities of alterations in elasticity of lung and chest wall or of ventilatory muscles cannot be ruled out leading to an improvement in FVC and other lung functions of swimmers. [15]

Actually, the response to swimming[15] may be expected to be different from the response to many other types of man's activities for the following reasons:

- Swimming is performed in horizontal position compared to the vertical position in other sports.

- The external pressure is higher as the density of the surrounding medium is higher than that of air, which is the usual external medium in other sports.

- Heat conductance of water is higher than that of air period

The ventilation is restricted in every respiratory cycle for one moment or the other, producing a condition of intermittent hypoxia. This intermittent hypoxia sets up the anaerobic process during swimming. The lactic acid levels in the blood go on rising resulting in "Lactic Oxygen deficit" [16]. This leads to the stimulation of the respiratory center in the medulla thereby increasing the respiration.

Further, the restricted ventilation experienced during swimming leads the swimmer to face intermittent hypoxia and this may result in alveolar hyperplasia and thus increased VC and FVC. [17]

The ability of the individual to inflate and deflate his lungs depends upon the strength of the thoracic and abdominal muscles, posture of the individual and the elasticity of the lungs [18]. Swimming increases this ability by a number of factors. It involves keeping the head extended which is a constant exercise of the Erector Spinae muscles and increases the vertical and anteroposterior diameter of the lungs as also supra spinatus which increases the antero -posterior diameter of the lungs. Besides the Sternocleidomastoid, Trapezius and the diaphragm are being constantly exercised. (19)

Inspiratory reserve volume reflects muscle strength, thoracic mobility and the balance between lung and chest elasticity. The muscles involved are the diaphragm and the accessory muscles of respiration. Swimmer has significantly higher IRV than non-swimmers. This can be explained on better functions of the inspiratory muscles and improved thoracic mobility.[19] According to Kubiak - Janczaruk E et al (2005) the parameters defining inspiratory airflows were significantly higher in swimmers who trained regularly for 7-8 years. This finding appears to be due to the effect of training on inspiratory muscles.[20]

Armour J et al (1993) reported that swimmers had significantly increased total lung 
capacity, vital capacity, and inspiratory capacity than the elite long distance athletes and elite control subjects. They also found that $\mathrm{FEV}_{1}$ was largest in swimmers. They suggest that the swimmers may have achieved greater lung volumes than either runner or control subjects not because of greater inspiratory muscle strength or differences in height, fat free mass, alveolar distensibility, age at commencement of training or sternal length or chest depth, but by developing physically wider chests containing an increased number of alveoli, rather than the alveoli of increased size. [21]

When we compared FEV1 as percentage of FVC we found that swimmers have lower value than the control group. Similar findings have been obtained by Shapairo and Paterson [22] in their studies on U.S. naval divers during rigorous physical training programme designed to build endurance. Ekblom and Hermansen [23] have also measured lung volumes in eight top athletes belonging to the Swedish National teams and have found lower values. The reason for this is that the training of muscles of shoulder girdle leads to an increase in the vital capacity by reason of the increased strength of the accessory muscles of inspiration. The change is not accompanied by a corresponding increase in the forced expiratory volume, so the proportion of the forced vital capacity which these subjects can expire in first second, tends to be relatively low [24].

SUMMARY AND CONCLUSIONS: Within the limitation of our study we can conclude that swimming is the best exercise for the respiratory system. Such a helpful exercise in milder form might help in rehabilitation of patients with compromised lung functions.

ACKNOWLEDGEMENTS: The contribution of the technical staff of the Department of Physiology MGM Medical College, Indore, MP, India is duly acknowledged. No funding/grant of any kind was obtained for this work.

DECLARATION OF INTEREST: The authors report no conflict of interest.

\section{REFERENCES:}

1. Ness GW, Cunningham DC, Eyon RB, Shaw DW. Cardio- Pulmonary Function in prospective competitive swimmer and their parents. J Appl Physiol 1974;37(1):27-31.

2. Newman F, Smalley BF, Thomson ML. A comparison between body size and Lung function of swimmer and normal school children. J Physiol 1961;156:9-10.

3. Sable Meenakshi,Vaidya S.M.,and Sable S.S.Comparative study of Lung Function of Swimmers and Runners Indian Journal of Physiology and Pharmacology 2012;56(1):100-104.

4. Mehrotra PK, Varma NS, Tiwari S, Kumar P. Pulmonary Functions in Indian Sportsman playing different sports. Ind J Physiol and Pharmac 1998;42(3):412-6.

5. Mehrotra PK, Verma NS, Yadav RK, Tewari S, Shukla N. Study of Pulmonary Functions in swimmers of Lucknow City. Ind J Physiol and Pharmac 1997;41(1): 83-6.

6. Cotes JE, Dabbs JM, Hall AM, Lakhera SC, Saunders MJ, Malhotra MS. Lung function of healthy young men in India: contributory roles of genetic and environmental factors. Proc R Soc Lond 1975; B191:413-25.

7. Das SK, Ray A. Predicted form of forced vital capacity in school boys. Ind J Physiol Allied Sci 1989;43: 88-92. 
8. Kamat SR, Sarma SB, Raju VRK. Indian norms for pulmonary functional observed values, predictive equations and inter correlations. J Assoc Physicians Ind 1977;25:531-40.

9. Miller GJ, Saunders MJ, Gilson RJC, Ashcroft MT. Lung function of healthy boys and girls in Jamaica in relation to ethnic composition, test exercise performance and habitual Physical activity. Thorax 1977;32:486-96.

10. Andrew GM, Becklake MP, Guleria JS, Bates DV. Heart and lung functions in swimmers and non-athletes during growth. J applied Physiol 1972;32:245-51.

11. Holmer I, Stein EM, Saltin B, Astrand PO. Hemodynamic and respiratory responses compared in swimming and running. J Appl Physiol 1974;37(1): 49-54.

12. Kaufmann DA, Swenson EW, Fencl J, Lucas A. Pulmonary function of marathon runners. Med Sci sports 1974;6:114-7.

13. Leith DE, Bradley M. Ventilaory muscle strength and endurance training. J App Physiol 1976;41:508-16.

14. Sinning W, Adrian MJ. Cardio respiratory changes in college women due to season of competitive basketball. J Appl Physiol 1968;25:720-24.

15. Lakhera S.C., Mathew L., Rastogi S.K. and Gupta J.S. Pulmonary Function of Indian Athletes and Sportsmen: Comparison with American Athletes. Indian Journal of Physiology and Pharmacology 1984;28(3):187-194.

16. Medbo JI, Mohn AZ, Tabata I. Anaerobic capacity determined by maximal accumulated O2 deficit. J Applied Physiol 1988; 64: 50-60.

17. Curistian W, Zauner, Benson Norms Y. Physical alterations in young swimmers during three years of intensive training. J Sports Med Phys Fitness 1981; 21: 179-185.

18. Zinman Rand Gaultier C. Maximal static pressures and lung volumes in young female swimmers. : Respir Physiol. 1986 May;64(2):229-39.

19. Pherwani Asha V., Desai A.G. and Solepure A.B. A study of Pulmonary Function of Competitive Swimmers. Indian Journal of Physiology and Pharmacology 1989; 33 (4): 228-232.

20. Kubiak-Janczaruk E. Spirometric evaluation of the respiratory system in adolescent swimmers. Ann Acad Med Stetin. 2005;51(2):105-13

21. Armour J, Donnelly PM, and Bye PT. The Large Lungs Of Elite Swimmers : an increased alveolar number. European Respiratory Journal. 1993 Feb; 6 (2) :237-47.

22. Shapairo W, Paterson JL. Effects of smoking and athletic conditioning on ventilator mechanisms including observation on the reliability of forced expirogram. Amer Rev Resp Dis 1962;85:191-9.

23. Ekblom B and Hearmansen L. Cardiac output in athletes. J Appl Physiol 1968;25: 619-25.

24. Cotes JE. Lung Function At Different Stages In Life, Including Normal Values. In: Lung Function Assessment and Application in Medicine, 2nd edn. Black well scientific Publication Oxford and Edinburgh, Great Britain, 1968: 345-91. 
Table 1. COMPARISON OF ANTHROPOMETRIC FACTOR

\begin{tabular}{|l|l|l|l|l|}
\hline Anthropometric factors & $\begin{array}{l}\text { Study group (n = 30) } \\
\text { Mean } \pm \text { S.D }\end{array}$ & $\begin{array}{l}\text { Control group } \\
(\mathbf{n}=\mathbf{3 0}) \\
\text { Mean } \pm \text { S.D }\end{array}$ & Value & RESULT \\
\hline Age (years) & $21.29 \pm 3.33$ & $21.4 \pm 3.20$ & 0.905 & Non- significant \\
\hline Height $(\mathrm{cms})$ & $176.59 \pm 5.69$ & $169.9 \pm 6.09$ & 0.000 & significant \\
\hline BSA $\left(\mathrm{m}^{2}\right)$ & $1.80 \pm 0.12$ & $1.68 \pm 0.13$ & 0.001 & significant \\
\hline Weight $(\mathrm{kg})$ & $65.63 \pm 8.62$ & $59.73 \pm 8.73$ & 0.013 & significant \\
\hline
\end{tabular}

Abbreviations: Body Surface Area, BSA

The mean difference is significant at $<.05$ levels

Table 2.COMPARISON OF LUNG FUNCTION PARAMETERS IN STUDY AND CONTROL GROUP

\begin{tabular}{|l|l|l|l|l|}
\hline Lung function parameters & $\begin{array}{c}\text { Study group } \\
\text { (n= 30) } \\
\text { Mean } \pm \text { S.D }\end{array}$ & $\begin{array}{l}\text { Control group } \\
\text { (n= 30) } \\
\text { Mean } \pm \text { S.D }\end{array}$ & p Value & \\
\hline $\begin{array}{l}\text { Inspiratory vital } \\
\text { capacity (litres) }\end{array}$ & $4.47 \pm 0.49$ & $3.46 \pm 0.27$ & 0 & Significant \\
\hline $\begin{array}{l}\text { Inspiratory reserve } \\
\text { volume (litres) }\end{array}$ & $2.20 \pm 0.46$ & $1.6 \pm 0.33$ & 0 & significant \\
\hline $\begin{array}{l}\text { Expiratory reserve } \\
\text { volume (litres) }\end{array}$ & $1.67 \pm 0.31$ & $1.32 \pm 0.35$ & 0.00 & significant \\
\hline Tidal volume (litres) & $0.77 \pm 0.27$ & $0.69 \pm 0.16$ & 0.82 & Non- Significant \\
\hline FVC (litres) & $4.61 \pm 0.48$ & $3.61 \pm 0.27$ & 0 & Significant \\
\hline FEV(litres) & $4.16 \pm 0.41$ & $3.31 \pm 0.26$ & 0 & Significant \\
\hline FEV1/FVC \% & $83.81 \pm 7.02$ & $91.2 \pm 5.53$ & 0.83 & Non- Significant \\
\hline MEF 25-75 \% & $5.14 \pm 0.86$ & $4.54 \pm 0.87$ & 0.60 & Non- significant \\
\hline MEF 25 \% & $2.97 \pm 0.76$ & $2.46 \pm 0.60$ & 0.02 & significant \\
\hline MEF 50 \% & $5.85 \pm 0.97$ & $5.26 \pm 1.13$ & 0.00 & significant \\
\hline MEF 75-85 \% & $7.67 \pm 1.42$ & $7.10 \pm 1.84$ & 0.64 & Non- significant \\
\hline PEFR & $8.27 \pm 1.23$ & $7.60 \pm 1.67$ & 0.41 & Non- significant \\
\hline
\end{tabular}

The mean difference is significant at $<.05$ levels 